\title{
Use of Staff Output Measures in the Wake County Public Library System
}

\author{
Val Lovett
}

As daily suppliers of statistics to the public, librarians might be assumed to be comfortable using statistical measurement as a tool to study staff work production, to evaluate staff effectiveness, to allocate staff resources, and to establish work standards. Hah! The profession is so ambivalent about statistical measurement of staff output that even comparative research studies are enshrouded with "Yes, buts." As for statistical measurement in one's own bailiwick, anxiety here is the most intense among administrators, managers, and staff alike.

I spent a day at the UNC-CH School of Information and Library Science trying to find articles or research about how output measures, work statistics, or any other measurements of staff output are used to construct budgets, allocate resources, plan new services, design new buildings, or request additional staff. I found articles about accuracy in reference work that once again sent shivers down my spine; I found information on how to construct a budget which avoided any specifics as to methods used to determine staff levels; I read some cryptic articles on what types of data are being collected, mostly in technical services departments, but I did not find any articles on the application of work statistics to the allocation of library resources or on the construction of budget requests. I was amazed.

Now I know everyone is looking at everyone else's data. Just last March, if one paused in one's daily routine, one could hear the sound of all the public library directors in this state ripping open the envelope that contained the North Carolina Division of State Library's annual compilation of public library statistics. One could hear the pages being rifled, the sighs of relief and the groans of disappointment, as each director compared his or her library to the closest rivals. One can imagine the acceptance of the good, the rejection of the bad, and the rationalization of the ugly.

Managers and administrators routinely use statistics to make decisions about library opera-

\footnotetext{
Val Lovett is Assistant Library Director, Administrative Services, for the Wake County Public Library System in Raleigh.
}

tions, but they do not use them openly nor do they use them enough. There is not a healthy balance between objective measurement and subjective evaluation. Although we are doing fine with the subjective assessments, we are too wishy-washy about the intelligent use of staff work production data in allocating resources. We talk about political realities, circumstances beyond one's control, and other stock phrases to wrap ourselves and our staffs in the cotton wool of unreality that statistics do not count. Then why are we counting?

The problem begins at home. Administrators should decide what work production statistics will be collected, how they will be evaluated, and how they will be used to make decisions. The data measurements chosen should relate directly to the library's mission statement, long range planning goals, and the current year's plan for action. These selections should be discussed thoroughly with the library staff, who are not only the primary collectors of the data, but usually the most resentful and suspicious of its use. No one likes to see results of his or her work reduced to numbers, especially when one does not know how those numbers will be used and may suspect they will be used against oneself and the status quo.

The manager must overcome this understandable staff resistance by using staff input to design and refine collection instruments. As the advocate for the use of this data, a manager must convince the staff of its responsibility for the validity of the statistics through the staff's reliability in the collection of the information. In my experience, the more reliant we are upon human beings to count ephemeral data, the more unreliable it is. For example, whether one uses a manual or an automated circulation system, there is something tangible to be counted. Contrasted with this, reference question tabulation is entirely dependent upon the accuracy of the staff in recording the data regardless of the method used in collecting it. When I talk with reference librarians about improving enumeration, they express their frustration in trying to keep an accurate count when their focus is on service to the patron. To them the patron services are the most important and I 
agree with that emphasis. The viewpoint often expressed by reference staff members is that if there are any doubts more staff is needed, then "they" ought to come to the library and work a few days.

It is vital to explain and discuss with the staff the role that data analysis has in decision making by library administration so that one can lower their frustration level. One can demonstrate the effect good data collection can have on the library's services. Also, the entire staff should analyze the data so that further refinement of the instrument and data evaluation is done by line and management staffs. This will build credibility for the process and help eliminate some of the mystique about use of the results.

Having done this, each year before data collection begins, the library administration projects the performance levels it believes the system should achieve in circulations per capita, turnover rate of the collection, books processed per hour, reference questions answered, story hour attendance, or percentage of the population registered as library patrons. Since data collection is an ongoing process, the administration is setting targets to reach for the upcoming year based upon both past performance and the annual plan

\section{... the more reliant we are upon human beings to count ephemeral data, the more unreliable it is.}

for the library system. As mentioned earlier, the chosen measurements should be an outgrowth of the mission statement and the goals of the library system. Then, data collection and evaluation become a method for assessing success in reaching the objectives set forth in the annual plan for the library system. Establishing these target levels for service achievement is similar to the private sector's setting goals for manufacturing and sales.

Now the administrator and the manager can discuss in detail the productivity targets for the branch or the department. They can work together from the goals established for the entire organization to the particular objectives set for the work unit. In addressing increased productivity, there is every reason to discuss increasing the work product by specific percentages or numbers, for example, increasing the circulation of juvenile non-fiction by thirty percent during the fiscal year. The administrator and manager can talk about the activities and resources needed to ac- complish this objective. A specific discussion is more productive than a vaguely stated direction such as "I want you to work on increasing circulation of the juvenile non-fiction materials." Working as a team, they can develop the necessary activities to achieve their objectives. This process can be used in all departments of the library, and it addresses the expected output measures for the individual work unit.

Staff output measures also can be used to establish work production standards for individuals as well as the entire unit. As managers, we must be fair to staff in expecting the same standard of work from all employees in the same jobs. The standard should be achievable, but also high in quality as well as quantity. Low or non-existent work production standards allow everyone to achieve a level of mediocrity. In my experience this has occurred most frequently in the clerical areas of the library profession such as typing catalog cards, editing records, filing cards, or shelving books.

Librarians become very defensive about establishing production standards for reference work, cataloging, or children's programming (i.e. "professional work"). I believe we have avoided developing performance standards for professional and para-professional positions for several reasons. The work performance standard in these areas is more difficult to establish, but not impossible. I think we resist turning our work into a statistical measure because we feel it demeans and oversimplifies what we do. Well, that argument is also applicable to those jobs in our libraries for which we are comfortable in using work standards.

All this discussion is the easy part. It is the prelude. Now one can begin to use the subjective impressions and empirical data together to understand the dynamics of the library system. When the empirical information is contrasted with the subjective, even though many subjective deductions are valid, there will be some surprises. The data will assist one in identifying specific differences among similar situations, the deviations from the mean and/or the median. Investigating these highs and lows can bring valuable insights, with resulting improvements in service. However, we must design those sophisticated means of measuring and quantifying that work because of the important information it can provide for library management decisions.

\section{Support Services Case Study}

In 1981, the cataloging and processing back$\log$ at Wake County Public Libraries was approxi- 
mately six weeks from receipt of the books, with some problem titles lingering on the shelves for as many as six months. Many titles, especially popular ones, were not received at library branches for months after they were available in bookstores. The branch staff bore the brunt of the public ire so that the working relationship between public services and support services was not genial. At that time the Support Services Division was processing approximately sixty thousand books per year. The Order Section used the Libris online ordering and accounting system. The Cataloging Section used OCLC/SOLINET. The card catalog had been closed on April 1, 1979, so the public catalog was published in microfilm format.

In late 1981, the library director set goals for the Support Services Division. He instructed the two managers of the division to reduce the turnaround time from the receipt of the books to the shipping of the books to the library branches to one week. The only exception was that high demand materials were to be ready to leave the building in one day. In addition, books were to be ordered and selected so they appeared on library bookshelves at the same time as they did in commercial bookstores.

The members of the Support Services Division achieved those goals within the year. They did this by meticulously flow charting each step of every operation. Then every step in the entire process was examined rigorously for its relevance and its efficiency. What happened in the Processing Unit is a good example of production standards helping to improve productivity.

The work done by the library processors at that time was the physical preparation of the book for the library shelves. Jacketing, pocketing and carding, accessioning, property stamping, and spine labeling represented the majority of the work. Book trucks were always conspicously ganged up in this area. There were no work production standards; everyone simply came to work and processed books. All the staff felt oppressed by the work that was piled up behind them.

For three months statistics were kept by individual processors. The work productivity achieved varied widely. There were several meetings of that staff with the head of cataloging who was the manager responsible for the unit. The staff set a work standard of three thousand books per month per staff member. After six months the individual work statistics were reviewed. The standard was found to be too high and was revised to twenty five hundred books per month per processor. This standard is in use today.
Today, only in the first rush of the fiscal year ordering do the processors have a few trucks backed up. However, they clear them very quickly. They are processing approximately one hundred fifty thousand books per year with only one additional staff person. When there is not enough work to do, they assist other support services units and library branches. During the past fiscal year, they have been instrumental in assisting smaller branches in linking collections to our CLSI system. During the upcoming year they will have linking duties for new books assigned to the unit. This change will necessitate revision of the work standards by that staff, the supervisor, and the manager.

This example illustrates how all the members of the Support Services Division turned them-

\section{.. we resist turning our work into a statistical measure because we feel it demeans and oversimplifies what we do.}

selves into customer-oriented, public services employees. Since 1981, the workload has risen from sixty thousand to one hundred fifty thousand new books representing approximately 11,000 titles. During these years, this staff also managed to convert retrospectively all title holding records to machine-readable format and install the CLSI circulation and public access catalog modules. The cataloging standards continued to be AACR2/MARC format, there were no compromises in the finished physical product, books are being received at the same time as the bookstores put them on their shelves, and the division has transferred three positions to public services.

The results have been improved service delivery to customers at a lower cost per unit of production, production expansion which kept pace with a growing book budget while also being flexible enough to do retrospective conversion, and library automation. The production standards helped improve the work of employees, helped eliminate non-productive employees, and through merit raises rewarded excellent employees.

It is also significant that the director did not tell managers and staff how to achieve the goals that he set. Since they had the expertise to make the choices, staff members made those decisions. The importance for administration is that the managers and staff made and adopted the changes rather than having them imposed upon 
them from outside the division. This is one way that staff output measures can improve productivity and service delivery without using additional dollars.

Ideally, if we understand the level of work an employee can achieve, there are many positive uses for that measure. Take, for example, a reference librarian. If we establish the number of reference questions which can reasonably be answered in an hour, we can extrapolate potential work load for the entire staff. Then we can construct schedules to meet demand from patrons. We can pinpoint when demand outstrips human resources and affects the quality of service the staff can deliver. We can identify those hours in the week when that critical point is reached. When the demand for service has outstripped available resources, we have the information to support additional personnel requests with the budget office. Those personnel requests can be more accurate than in the past. For example, one might request two half-time positions to target overloaded nights and weekends, rather than a full-time position working some hours where demand is less critical.

\section{Reference Case Study}

The statistics from Table 1 will be used to discuss several points about staff output measures. I must confess that Wake County Public Libraries does not have a performance standard for the number of reference questions per hour for a staff member. Therefore, we have to use the information available to us. [Note: I am not aware of any existing standard in use for reference questions, although I am interested in the possibility of developing one.]

During the preparation of the library system's personnel request for the FY 1991 budget, there were a number of requests submitted by library branches for additional personnel to maintain existing levels of service. There was a subjective opinion that Branch $\mathrm{C}$ should have the first priority position in that request because it is so busy. The data reveals that although it does field more questions per hour than any other branch, there is a relatively comfortable level of average demand on each staff member. The same cannot be said of Branch B. Because these statistics do not include directional questions, instructions on the use of equipment or reference tools, making change, or other requests that take time, we knew empirically and subjectively that Branch B should have the priority position in new staff requests.

Budget analysts do not conceptualize "service" well at all. A statement that reference service at the branch was deteriorating because the demand for service is higher than the staff can handle does not mean much to my budget analyst. Even if I had stated that at peak hours the staff might as well stand behind the desk and randomly throw books at the patrons, while I might have made a point, I have not proven it. I must translate service delivery into the language of the budget administrator, or I will be on the losing end in the struggle for a greater share of the budget dollar. Therefore, if I can translate service into a statistical measure and relate it to a work standard (even if it is more than a little subjective), then the budget analyst and I can examine the staffing issue based upon the reasonably achievable work in a staff hour. A variant of Table 1 was used in the budget document for FY 1991.

In FY 1991, Wake County added more than two hundred new staff positions, most of them related to capital projects, such as the new Public Safety Center which was coming online. There were only ten positions funded in the County to deal with growth in existing services. One of those positions was a new professional position for Branch B. This is an example of how staff output measures can add more dollar resources.

Another point to be made is that Branch B helped itself by positioning itself. At the end of the previous fiscal year the branch manager told me he felt the staff was seriously undercounting reference questions. We talked about the importance that data had on budget requests. He included activities to improve data collection in his work

TABLE 1.

\begin{tabular}{lrrr} 
& $\begin{array}{c}\text { Adult Services Staff Output Measures Estimates for Reference Questions } \\
\text { in Selected Wake County Public Library Branches, FY 1990 }\end{array}$ \\
\hline & Branch A & Branch B & Branch C \\
\hline Staff Hours/Year & 16,000 & 5,000 & 16,000 \\
Hours Open/Year & 3,600 & 3,400 & 3,600 \\
Ref. Quest./Year & 49,672 & 40,091 & 60,160 \\
Ref. Quest./Staff Hr. & 3.10 & 8.01 & 3.76 \\
Ref. Quest./Hr. Open & 13.8 & 11.8 & 3.20 \\
\hline
\end{tabular}


plan. As a result, the Adult Services Department recorded fifteen thousand additional questions as answered.

In looking at the data in Table 1, several other staff members have the subjective reaction that we are either undercounting or using an invalid sampling technique. A conversation among the director, the Adult Services Coordinator, and myself revealed that the sampling techniques had been developed primarily to provide collection development information for Adult Services. The director and I, however, primarily use them for measurement of work load and service delivery, budget work, and future planning for staff size. We agree that we need to do more testing and refinement of our sampling instrument and will be working on that in the upcoming year.

\section{Allocation/Reallocation of Resources}

The toughest part of any administrator's job is the allocation or reallocation of resources. Output measures assist in these decisions. Until three years ago the Wake County Public Libraries System only divided its materials budget by the categories of adult, children's, continuations, and periodicals. Branches purchased what they needed. In FY 1989, at the request of branch heads, the budget was subdivided into individual branch budgets for adult materials. Since then this has been done for children's materials. Because we believe that resources should flow to the areas of highest use, the branch managers in the first year advocated a strict appropriation of monies based on circulation. With experience, however, the appropriation has become less absolute, as we also must acknowledge that there is a floor below which a branch budget cannot fall without totally crippling service. In my opinion, a viable public library branch must have a minimum materials budget of $\$ 15,000$. So, we combine both objective measures and subjective knowledge in establishing branch budgets.

Just as the manager of Branch B positioned her library to receive additional personnel by increasing the accuracy of its data collection, a branch head can affect the amount of additional monies allocated beyond its budget floor by purchasing materials which will circulate well and by keeping the collection weeded so that the turnover rate will not be affected by dead wood. Wake County has a tiered library system with no main library. Regional branches located geographically throughout the county in population centers provide additional resources for smaller popular lending libraries. Therefore, smaller libraries which have spent monies on books for which they had one or two potential readers instead of borrowing the title from a regional branch will not have the same service return as the smaller library which concentrates on purchasing popular reading while borrowing more eclectic items from the regional libraries. Appropriate selection can raise the percentage of the gross circulation the branch contributes to the system. Circulation goes up, patrons receive more service; patrons receive more service relative to other branches, the branch receives more discretionary money for books. This outcome reflects the effect that staff can have in bringing more resoures to their area of responsibility. By increasing the level of service delivered relative to the system, reallocation of resources, in this case book monies, brings more dollars to that service point. The book circulation output measure can be used as one of the assessment factors in evaluating the branch manager's selection skills.

\section{Conclusion}

When an administrator uses statistical measures to make decisions, there will be unhappy campers. For better or for worse, each manager or staff member perceives his or her situation as unique, outside the statistical parameters, and having an incredible number of extenuating circumstances - which he or she will repeatedly share with you. In a profession where we give very personalized, customized service to individuals, it is difficult to accept that all those individualized units of service do add up to produce bell curves, means, medians, standard deviations, and chi squares. It seems inhuman that it comes down to that. Perhaps that is why we have this dichotomy within ourselves that statistics apply to everyone else, but "I need to explain why my situation is different, so the statistics don't really count."

I advocate a team approach in developing quantitative measurements for a library system. It helps everyone understand that statistics are more than numbers. If collected properly, they can create a vivid picture of the effort a staff makes in serving its community. They can be persuasive means of securing additional financial support. Together, with subjective observations, they can assist us in making better decisions about resource allocations. Staff will perceive decisions made by managers as more rational and more fair. As with Branch B, perhaps they will use work performance measures to explain why "my situation is different" and why "I do need the additional resources requested." 


\section{Jogin F. Blowir}

\section{A BOY'S WAR}

Paxton Davis

In this sequel to his Being a Boy, Davis opens with his first year as a cadet at Virginia Military Institute. A Boy's War follows Davis as he enters the Army during

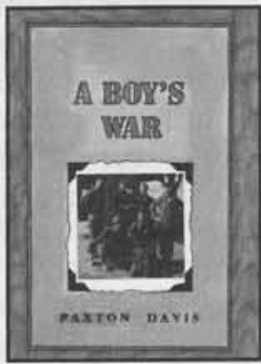
World War II and continues to his twentyfirst birthday - two weeks after his release from the Army.

ISBN 0-89587-079-7. $\$ 17.95$ hardcover Black-and-white photographs.

\section{GOLFING IN THE CAROLINAS}

William Price Fox

Fox-author of golfing articles for Sports Illustrated, Golf Club, Southern and writer-inresidence at the University of South Caro-

lina-describes the 50 best golf courses in North and South Carolina.

100 color photographs. ISBN 0-89587-078-9. $\$ 39.95$ hardcover.

\section{MORE MURDER IN THE CAROLINAS Nancy Rhyne}

The sequel to Rhyne's popular Murder in the Carolinas. A collection of fourteen famous murders committed in North and South Carolina.

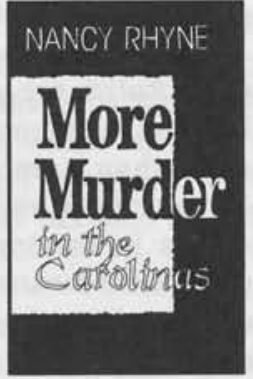

ISBN 0-89587-075.4. \$8.95 paperback.

DEAN SMITH: A BIOGRAPHY

Thad Mumau

Foreword by Michael Jordan

This authorized biography of Dean Smith, basketball coach of the University of North Carolina Tarheels, traces Smith's life and career. This book includes interviews with former players, opposing coaches and former assistants.

ISBN 0.89587-080-0. $\$ 18.95$ hardcover. Black-and-white photographs.

\section{TOURING THE WESTERN NORTH} CAROLINA BACKROADS

Carolyn Sakowski

Useful as a history or a guidebook to western North Carolina, this book traces 21 tours through the out-ofthe-way places from Blowing Rock to Flat Rock, Roan Mountain

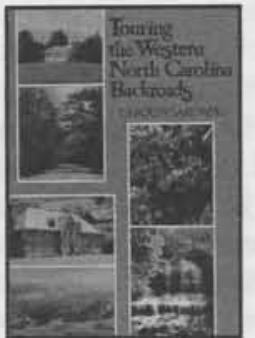
to Stone Mountain, Murphy to Sparta. Over 120 black-and-white photographs. ISBN 0-89587-077-0 $\$ 14.95$ trade paperback.

\section{TAFFY OF TORPEDO JUNCTION}

Nell Wise Wechter

A reissue of the 1957 young adult classic about thirteen-year-old Taffy's adventure with German spies on the Outer Banks of North Carolina during World War II.

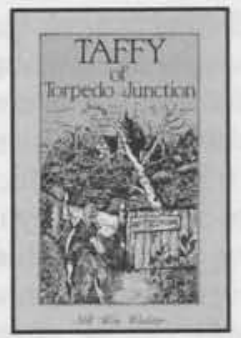

ISBN 0-89587-076-2. \$7.95 paperback. Ages 10-14

Blair books can be ordered directly from the publisher or from

Ingram Book Co., Baker \& Taylor, Koen Book Distributors, Broadfoot's or other wholesalers. Blair allows a $20 \%$ discount for libraries.

John F. Blair, Publisher • 1406 Plaza Drive · Winston-Salem, North Carolina 27103 • 1-800-222-9796 